\title{
Association between Indoor and Outdoor Air Pollution and Adolescent Asthma from 1995 to 1996 in Taiwan
}

\author{
Tsu-Nai Wang, ${ }^{*}$ Ying-Chin Ko, ${ }^{* 1}$ Yu-Ying Chao, ${ }^{*}$ Chi-Chih Huang, $\dagger$ and Ruey-Shiung Lin $\ddagger$ \\ * School of Public Health, Institute of Medicine, Kaohsiung Medical College, Kaohsiung, Taiwan, Republic of China; \\ $\uparrow$ Department of Internal Medical, Kaohsiung Medical College, Kaohsiung, Taiwan, Republic of China; and \$Institute of Epidemiology, \\ College of Public Health, National Taiwan University, Taipei, Taiwan, Republic of China
}

Received February 8, 1999

\begin{abstract}
The study aim was to estimate the contribution of indoor and outdoor air pollution to the 1-year prevalence of adolescent asthma after personal susceptibility and other potential risk factors were taken into account. A large-scaled cross-sectional study was conducted among 165,173 high school students aged 11 to 16 years in the different communities of Kaohsiung and Pintong in Taiwan, from October 1995 to June 1996. Each student and his/her parents participating in the study completed a video and a written International Study of Asthma and Allergies in Childhood (ISAAC) questionnaire about symptoms of wheezing and allergies, passive smoking, and demographic variables. After adjustment for potential confounders, adolescents exposed to cigarette smoking (odds ratio $=1.29,95 \%$ confidence interval (CI), 1.17-1.42) and environmental tobacco smoke (odds ratio $=1.08,95 \%$ CI, 1.05-1.12) were found to suffer from asthma at an increased frequency. We observed a statistically significant association between outdoor air pollution and asthma, after controlling for potential confound variables. Total suspended particulate, nitrogen dioxide, carbon monoxide, ozone, and airborne dust particles all displayed an independent association with asthma, respectively. There were no selection biases in this communitybased study, which provides evidence that passive smoking and long-term, high average outdoor air pollution are independent risk factors of asthma. (c) 1999 Academic Press
\end{abstract}

Key Words: asthma; indoor; outdoor; air pollution; environmental tobacco smoke.

\footnotetext{
${ }^{1}$ To whom correspondence and reprint requests should be addressed at School of Public Health, Kaohsiung Medical College, 100, Shih-Chuan 1 Rd, Kaohsiung, Taiwan, Republic of China. Fax: (886) 7-3162725. E-mail: ycko@mail.nsysu.edu.tw.
}

\section{INTRODUCTION}

The prevalence of asthma for schoolchildren has been increasing gradually in Taiwan. Air pollution traceable to sources such as industry, traffic, and residential buildings has also increased massively throughout the island during these years. No demarcation exists between plants and residential quarters in Taiwan (Ko, 1996). Although air contaminants may contribute to clinical asthma, there are at present no data on the relation between air pollution exposure and adolescent asthma in Taiwan. It is necessary to study the adverse effects of air pollution on asthma.

There were difficulties in assessing any association between air pollution and health effects for several reasons: (a) individual or population exposure is unknown, (b) the effect of air pollution on health is difficult to assess, as environmental air pollution may cause or worsen asthma, and (c) many confounders, such as occupational exposure, smoking habit, etc., may be involved. Many studies documented the association between short-term, high dose air pollution exposure and acute health effects. Fewer studies addressed the question of long-term air pollution concentration. The Swiss schoolchild study and other cross-sectional surveys suggest an association between respiratory health indicators and long-term air pollution exposure (Braun-Fahrlander et al., 1997; Schwartz et al., 1989). But there is also little evidence in the world literature that asthma prevalence or incidence is related to ambient air pollution exposure. Outdoor exposure such as truck traffic in a residential street was associated with asthma in a German study (Duhme et al., 1998), which was not a proper indicator for assessing outdoor air pollution. The long-term, high average air pollution concentration and increased prevalence of asthma are carried out in this communities-based study. 
Particulate air pollution refers to a mixture of solid and liquid particles suspended in the air. More recent epidemiologic studies have shown that present ambient concentration particles, $\mathrm{SO}_{2}$, acid aerosols, and other particles are associated with increased respiratory morbidity and mortality (von Mutius et al., 1995). Particulate matter less than $10 \mu \mathrm{m}$ in aerodynamic diameter $\left(\mathrm{PM}_{10}\right)$ deposits into the pulmonary region of lung and damages the airways where gas exchange takes place. Ozone is a powerful oxidant and as an air pollutant has been shown to induce pulmonary fibrosis (Chitano et al., 1995) and increased probability of asthma attacks (Whittemore et al., 1980). The most consistent relationship was found with particulate air pollution and ozone. Increasing $\mathrm{SO}_{2}$ concentration was found associated with prevalence of asthma and respiratory symptoms in school students who lived in areas of severe air pollution (Neas et al., 1995). Some epidemiological data indicated weak or no association between sulfur dioxide and mortality (Dockery et al., 1992). Nitrogen dioxide is a gaseous product of combustion from both stationary sources and motor vehicles. There is a large discrepancy in studies of the effects of exposure to $\mathrm{NO}_{2}$ on lung function and airway response for healthy subjects and asthmatics. Only a few studies have directly addressed the association between $\mathrm{NO}_{2}$ concentration in outdoor air and respiratory illness (Duhme et al., 1998). Several studies have examined the adverse effects of $\mathrm{CO}$ on spirometric end points (Evans et al., 1988; Lebowitz et al., 1987;). Because the mechanism for the effect on respiratory diseases is not yet well understand, interpretation of these finding must be recognized by biological plausibility.

Concern has arisen in recent years about indoor air pollution as a risk factor of asthma. Pollutants in the home are numerous, frequently from sources (Chang et al., 1989; Dales et al., 1991; Dijkstra et al., 1990; Hosein et al., 1989; Peat et al., 1996;), such as tobacco smoking, dust mites, dampness, and pets. The role of ETS as a cause of asthma, however, remains less certain, especially in adolescents (Cunningham et al., 1996). But many studies have shown a statistically significant relationship between passive smoking and childhood asthma (Forastiere et al., 1992; Newman-Taylor et al., 1995), but some have not (Chinn et al., 1991; Sherman et al., 1990). The exposure to environmental tobacco smoke (ETS) is associated with wheezing symptoms, medical therapy for wheezing, and wheezing-related emergency departure visits (Cunningham et al., 1996), especially for children whose mothers smoked (Stoddard et al., 1995).

This is the first study to assess comprehensive risk factors for asthma using the ISAAC questionnaire.
The study aim was to estimate the contribution of indoor and outdoor pollution to the 1-year prevalence of adolescent asthma after personal susceptibility and other potential risk factors were taken into account to reduce the risk of accidental confounding.

\section{MATERIALS AND METHODS}

\section{Study Population}

Our population sample included the pupils of all three grades in 123 high schools of the Kaohsiung and Pintong areas in Taiwan $(n=170,457)$. Each student and his/her parents participating in this crosssectional study completed a video and a written questionnaire between October 1995 and June 1996. In all 165,173 questionnaires were completed by students and their parents.

\section{Written Questionnaire}

Respiratory and allergic illness and symptom responses obtained from the written questionnaire were considered. Current wheeze, nocturnal dry cough apart from infection, wheezing after exercise, sneeze, conjunctivitis symptoms and asthma, atopic dermatitis, and rhinitis were diagnosed by a doctor.

Wheezing was defined as a positive response to the question: "Has your child had wheezing or whistling in the chest in the last 12 months?" Nocturnal dry cough required a positive response to the question: "In the past 12 months, has your child had a dry cough at night, apart from a cough associated with a cold or fever infection?" Sneezing was an answer to the question: "In the past 12 months, has your child had problem with sneezing or a runny or blocked nose when he/she did not have a cold or the flu?" Conjunctivitis symptoms were defined as a positive response to the question: "In the past 12 months, has your child had itchy or irritated eyes?"

The questions answered by parents also concerned sociodemographic characteristics, the habits of cigarette smoking and alcohol drinking by the students (yes or no), ETS (at least one family member who lived with the student has a smoking habit), total quantity of family members who smoke (no, less than one pack, more than one packs for 1 day), the daily use of Chinese incense in the home (yes or no), and students exercise habits (no, seldom, usually).

\section{Video Questionnaire}

The video questionnaire (Shaw et al., 1992) developed by the International Study and Asthma and Allergies in Childhood (ISAAC) consisted of five 
sequences of young people displaying signs of asthma. The scenes depicted:

1. Moderate wheezing at rest,

2. Wheezing and shortness of breath after exercise,

3 . Nocturnal waking with wheezing or whistling,

4. Nocturnal waking with cough,

5. Severe wheezing and shortness of breath at rest.

After each sequence, the children were asked to specify whether their breathing had been like the person in the video. Following each scene a question was asked, which was similar in format to the following:

Has your breathing ever been like this at any time in your life? Yes/No

If yes: In the past 12 months? Yes/No

If yes: How many time in every month?

Each question was presented in written form on the screen, and also printed on a one-page answer sheet which was completed during screening the video. The term "asthma" was not mentioned during the video until all five sequences had been completed. The students filled the ISAAC questionnaire after watching the videotape.

The definition of asthma in our study is a positive response to any of questions 1 to 5 in the last year (1996-1-year prevalence) in the video program. The definition of nonasthma is no positive response to questions 1 to 5 throughout life. In order to reduce recall bias, 9890 students who had any one positive response before 1995 but not one during the last year (1995-1996) to the questions will be excluded in this study. Only 155,283 students were included to study the effects of potential risk factors.

\section{Outdoor Air Pollution Monitoring}

Air pollution data were extracted from the Taiwanese Environmental Protection Administration's aerometric data bank. Only 24 communities set up the air monitoring stations covering 117,080 students $(72.6 \%)$ in Kaohsiung and Pintong, excluding sparsely populated rural districts and the aboriginal reservation areas. These small communities which are mostly located in the suburbs did not set up any air pollution station. Carbon monoxide, nitrogen dioxide, $\mathrm{PM}_{10}$, sulfur dioxide, and airborne dust levels were monitored at 16 stations in the Kaohsiung and Pintong areas during the study period. Ozone, total suspended particulate matter, and hydrocarbon compounds were monitored at 15, 18, and 11 stations, respectively. Only students who lived in a community covered by air monitoring stations were included into the study of an association between outdoor air pollution and adolescent asthma.
Average air pollution levels for the year of 1996 were calculated. The cutoff concentrations were determined from the median values among all monitoring stations for the analysis of air pollution effects. The cutoff $\mathrm{CO}, \mathrm{NO}_{2}, \mathrm{SO}_{2}$, airborne dust, $\mathrm{O}_{3}$, TSP, and hydrocarbon compounds were $0.80 \mathrm{ppm}, 0.028 \mathrm{ppm}, 0.013$ ppm, 7.6 ton $/ \mathrm{km}^{2} /$ month, $0.022 \mathrm{ppm}, 181 \mu \mathrm{g} / \mathrm{m}^{3}$, and $0.45 \mathrm{ppm}$, respectively (Table 1). There was collinearity between $\mathrm{PM}_{10}$ and $\mathrm{SO}_{2}$. The cutoff value of $\mathrm{PM}_{10}$ was taken to be $80 \mu \mathrm{g} / \mathrm{m}^{3}$. To analyze the association between asthma and air pollution we restricted pollution exposure data to students.

\section{Statistical Analysis}

Logistic regression was used to assess the association between possible risk factors and asthma. A multiple logistic regression analysis was used to determine the independent effects of several suspected risk factors of asthma, after adjusting for age, sex, parents' education, and area of residence. Adjusted odds ratio and $95 \%$ confidence intervals (CI) for each were calculated from the estimated regression coefficients for the exposure variables and their associated standard errors. Covariates included in the regression Model 1 were indicator variables for the schoolchild's sex, age, resident area, habits of exercise, smoking, and alcohol, parents' educational level, incense use at home, and ETS. The annual average concentration of each pollutant was calculated (Table 1). The cut points of exposure levels for the students were classed according to the median of pollutant values among all air monitoring stations. Pollutant-related odds ratios for asthma were estimated by including Model 1 into the multiple regression analysis (from Models 2 to 8). We used the SAS software package version 6.0 for our computations.

\section{RESULTS}

In all 165,173 questionnaires were completed. The response rate was approximately $96.9 \%$ in all centers. The self-reported lifetime prevalence of asthma was $18.5 \%(30,557 / 165,173)$, 1-year prevalence of asthma was $12.5 \%(20,637 / 165,173)$, and the rate for multiple attacks within a month was $5.2 \%(8643 / 165,173)$. In order to reduce recall bias, 1-year prevalence of asthma instead of lifetime prevalence of asthma was used in the present study. We analyzed how the 1996 asthma prevalence was related to 1996 air pollution levels and other factors. 
TABLE 1

Self-Reported Asthma Prevalence and Air Pollutants (1995-Annual Means) by Study Community

\begin{tabular}{|c|c|c|c|c|c|c|c|c|c|c|c|}
\hline Community & $\begin{array}{c}n \\
(117,080)\end{array}$ & Asthma (\%) & $\begin{array}{c}\text { Population } \\
\text { density }^{a}\end{array}$ & $\begin{array}{c}\mathrm{CO} \\
(\mathrm{ppm})\end{array}$ & $\begin{array}{l}\mathrm{NO}_{2} \\
(\mathrm{ppm})\end{array}$ & $\begin{array}{l}\mathrm{PM}_{10} \\
\left(\mu \mathrm{g} / \mathrm{m}^{3}\right)\end{array}$ & $\begin{array}{l}\mathrm{SO}_{2} \\
(\mathrm{ppm})\end{array}$ & $\begin{array}{c}\mathrm{O}_{3} \\
(\mathrm{ppm})\end{array}$ & $\begin{array}{c}\text { Airborne dust } \\
\left.\text { (ton } / \mathrm{km}^{2} / \mathrm{month}\right)\end{array}$ & $\begin{array}{c}\text { TSP } \\
\left(\mu \mathrm{g} / \mathrm{m}^{3}\right)\end{array}$ & $\begin{array}{c}\mathrm{CH} \\
(\mathrm{ppm})\end{array}$ \\
\hline \multicolumn{12}{|c|}{ Kaohsiung City } \\
\hline Tsoying & 6155 & 13.68 & 5.96 & 0.80 & 0.025 & 75.20 & 0.011 & 0.024 & 7.79 & 151.75 & 0.33 \\
\hline Kushan & 2975 & 18.66 & 7.47 & - & - & - & - & - & 7.86 & - & - \\
\hline Nantzu & 6936 & 14.35 & 5.15 & 0.60 & 0.029 & 87.08 & 0.008 & 0.018 & 9.37 & 211.49 & 0.34 \\
\hline Sanmin & 14121 & 15.42 & 16.72 & 0.93 & 0.031 & 72.53 & 0.001 & 0.021 & 9.56 & 237.82 & 1.52 \\
\hline Hsinhsing & 1501 & 12.59 & 34.33 & 1.49 & - & - & - & - & 7.92 & 172.20 & 0.83 \\
\hline Chienchin & 3350 & 15.43 & 20.04 & 0.95 & 0.028 & 90.24 & 0.013 & 0.023 & 7.53 & 180.77 & - \\
\hline Linya & 14289 & 20.74 & 26.46 & - & - & - & - & - & 10.08 & - & - \\
\hline Chiching & 1234 & 9.72 & 23.10 & 0.66 & 0.027 & 107.73 & 0.017 & 0.023 & 7.09 & 192.27 & 0.45 \\
\hline Chienchen & 9677 & 12.17 & 10.70 & - & 0.034 & 97.14 & 0.018 & - & 10.10 & 171.94 & 0.51 \\
\hline Hsiaokang & 7587 & 14.04 & 3.34 & 1.07 & 0.035 & 96.00 & 0.023 & 0.019 & - & - & 0.44 \\
\hline \multicolumn{12}{|c|}{ Kaohsiung County } \\
\hline Fengshan & 13009 & 14.51 & 11.27 & 1.06 & 0.034 & 103.08 & 0.020 & 0.021 & 4.89 & 200.10 & - \\
\hline Meinung & 1907 & 14.79 & 0.42 & 0.55 & 0.016 & 89.95 & 0.004 & 0.031 & - & - & - \\
\hline Linyuan & 3614 & 11.46 & 2.12 & 0.65 & 0.023 & 112.81 & 0.018 & 0.025 & 5.32 & 155.86 & 0.37 \\
\hline Taliao & 3803 & 10.48 & 1.51 & 0.37 & 0.025 & 105.17 & 0.015 & 0.022 & 4.33 & 159.82 & - \\
\hline Jenwu & 2792 & 14.27 & 1.13 & 0.75 & 0.029 & 94.68 & 0.018 & 0.017 & 4.89 & 149.52 & 0.53 \\
\hline Chiaotou & 1456 & 8.04 & 1.45 & 0.66 & 0.023 & 83.86 & 0.008 & 0.017 & 6.60 & - & 0.34 \\
\hline Kangshan & 790 & 16.58 & 1.84 & - & - & - & - & - & - & 226.21 & - \\
\hline Luchu & 1647 & 17.36 & 1.08 & - & - & - & - & - & - & 112.81 & - \\
\hline Yung-an & 452 & 7.96 & 0.56 & - & - & - & - & - & - & 192.93 & - \\
\hline Tashe & 790 & 16.58 & 1.18 & - & - & - & - & - & - & 184.04 & - \\
\hline \multicolumn{12}{|c|}{ Pingtung County } \\
\hline Pingtung & 11447 & 12.95 & 3.30 & 0.82 & 0.028 & 102.92 & 0.007 & 0.026 & 4.94 & 117.77 & 0.36 \\
\hline Chaochou & 2792 & 9.99 & 1.14 & 0.56 & 0.021 & 103.34 & 0.005 & 0.002 & 5.73 & 117.59 & - \\
\hline Hengchun & 954 & 13.10 & 0.23 & 0.21 & 0.001 & 19.40 & 0.000 & 0.032 & - & - & - \\
\hline Wantan & 2254 & 5.28 & 0.92 & - & - & - & - & - & - & 114.59 & - \\
\hline Median & & & & 0.80 & 0.028 & 91.00 & 0.013 & 0.022 & 7.60 & 181.00 & 0.45 \\
\hline
\end{tabular}

${ }^{a}$ Population density (thousands people $/ \mathrm{km}^{2}$ ).

\section{Demographic Characteristics of Adolescent Asthma}

Table 2 displays the univariate analysis of demographic characteristics of young adolescent asthma sufferers. Young boy students whose parents were highly educated and lived in Kaohsiung city showed a significant excess of asthma. There was a dose-response relationship between asthma and parents' reported air pollution. The students' habits of cigarette smoking, alcohol drinking, and infrequent physical exercise were significantly associated with asthma. These variables would be included in the multiple regression to control potential confounders.

\section{Indoor Air Pollution}

Passive smoking and using of Chinese incense were included among the indoor pollutants surveyed. The odds ratio was $1.13(95 \%, \mathrm{CI}=1.07-1.19)$ among persons who were exposed to more than a pack/day quantity of passive smoking. However, a negative association was observed between adolescent asthma and Chinese incense (Table 3).

\section{Outdoor Air Pollution}

Table 4 displays the univariate association of young adolescent asthma and outdoor air pollution. Total suspended particulate, sulfur dioxide, nitrogen dioxide, carbon monoxide, ozone, and airborne dust were all found to be significantly associated with adolescent asthma. But $\mathrm{PM}_{10}$ and hydrocarbon compounds were not. The frequency of high level $\mathrm{PM}_{10}$ concentrations $\left(\geq 80 \mu \mathrm{g} / \mathrm{m}^{3}\right)$ was lower among asthma patients than among nonasthmatic adolescents.

\section{Multivariate Analysis}

Table 5 shows that the demographic characteristics and indoor air pollution factors were included in the same regression model (Model 1). Cigarette smoking and passive smoking were both strongly associated with asthma, if other risk factors were controlled. The effects of demographic variables on asthma were unchanged whether or not covariates were controlled.

Pollutant-related odds ratios for asthma were estimated by including Model 1 into the multiple regression analysis (from Models 2 to 8) (Table 6). The cutoff 
TABLE 2

Univariate Analysis of the Characteristic of Adolescent Asthma

\begin{tabular}{|c|c|c|c|c|}
\hline Variables & $\begin{array}{c}\text { Asthma } \\
n(\%)\end{array}$ & $\begin{array}{c}\text { Non-asthma } \\
n(\%)\end{array}$ & $\mathrm{OR}^{a}$ & $95 \% \mathrm{CI}^{b}$ \\
\hline \multicolumn{5}{|l|}{ Sex } \\
\hline Female & $9422(12.01)$ & 69032 (87.99) & 1 & \\
\hline Male & $11215(14.60)$ & $65614(85.40)$ & $1.25^{* *}$ & $(1.22-1.29)$ \\
\hline \multicolumn{5}{|l|}{ Age } \\
\hline $11-12$ years & $5217(14.85)$ & 29925 (85.15) & 1 & \\
\hline $13-14$ years & $13741(13.05)$ & 91563 (86.95) & $0.86^{* *}$ & $(0.83-0.89)$ \\
\hline $15-16$ years & 1679 (11.32) & $13159(88.68)$ & $0.73^{* *}$ & $(0.69-0.78)$ \\
\hline \multicolumn{5}{|l|}{ Residence } \\
\hline Pintong County & $3722(9.58)$ & 35149 (90.42) & 1 & \\
\hline Kaohsiung County & $6188(12.92)$ & $41712(87.08)$ & $1.40 * *$ & $(1.34-1.46)$ \\
\hline Kaohsiung City & 10727 (15.66) & $57786(84.34)$ & $1.75^{* *}$ & $(1.69-1.82)$ \\
\hline \multicolumn{5}{|l|}{ Parents'education } \\
\hline Primary school & $3515(10.86)$ & 28865 (89.14) & 1 & \\
\hline High school & $12664(13.25)$ & 82913 (86.75) & $1.25^{* *}$ & $(1.21-1.31)$ \\
\hline College & $4458(16.31)$ & 22869 (83.69) & $1.60 * *$ & $(1.53-1.68)$ \\
\hline \multicolumn{5}{|l|}{ Exercise habit } \\
\hline No & 3139 (15.19) & $17522(84.81)$ & 1 & \\
\hline Seldom & $9961(13.20)$ & $65482(86.80)$ & $0.85^{* *}$ & $(0.81-0.89)$ \\
\hline Usually & 7487 (12.73) & $51332(87.27)$ & $0.81 * *$ & $(0.78-0.85)$ \\
\hline \multicolumn{5}{|l|}{ Cigarette smoking } \\
\hline No & $19864(13.17)$ & 131016 (86.83) & 1 & \\
\hline Yes & $696(18.49)$ & $3068(81.51)$ & $1.50^{* *}$ & $(1.38-1.63)$ \\
\hline \multicolumn{5}{|l|}{ Alcohol drinking } \\
\hline No & 19927 (13.12) & $131943(86.88)$ & 1 & \\
\hline Yes & $620(23.46)$ & $2023(76.54)$ & $2.03^{* *}$ & $(1.85-2.22)$ \\
\hline
\end{tabular}

${ }^{a} \mathrm{OR}$, odds ratio.

${ }^{b} \mathrm{CI}$, confidence interval.

$* * P<0.05$.

concentrations, of the air pollutants were the same as those in Table 4 . We found that asthma was significantly related to high levels of total suspended particulate matter, nitrogen dioxide, carbon monoxide, ozone, and airborne dust $(P<0.01)$, upon controls for Model 1. The adjusted odds ratios were 1.29 $(95 \% \quad$ CI $=1.24-1.34), \quad 1.08 \quad(95 \% \quad$ CI $=1.04-1.13), \quad 1.15$

TABLE 3

Univariate Analysis of Adolescent Asthma and Indoor Air Polluation

\begin{tabular}{lccll}
\hline \multicolumn{1}{c}{ Asthma } \\
Variables & $n(\%)$ & $\begin{array}{c}\text { Non asthma } \\
n(\%)\end{array}$ & OR & $95 \% \mathrm{CI}$ \\
\hline ETS & & & & \\
$\quad$ No & $8425(13.18)$ & $55493(86.82)$ & 1 & \\
$\quad$ Yes & $12212(13.37)$ & $79154(86.63)$ & 1.02 & $(0.99-1.05)$ \\
Quantity & & & & \\
$\quad$ No & $9106(13.28)$ & $59474(86.72)$ & 1 & \\
$\quad \leq 1$ pack/day & $9800(13.08)$ & $65135(86.92)$ & 0.98 & $(0.95-1.01)$ \\
$\quad$ 1 pack/day & $1731(14.71)$ & $6841(86.29)$ & $1.13^{* *}$ & $(1.07-1.19)$ \\
Chinese incense & & & & \\
$\quad$ No & $11244(13.99)$ & $69145(86.01)$ & 1 & \\
$\quad$ Yes & $9236(12.56)$ & $64297(87.44)$ & $0.88^{* *}$ & $(0.86-0.91)$ \\
\hline
\end{tabular}

$* * P<0.01$
$(95 \% \mathrm{CI}=1.10-1.20), 1.11(95 \% \mathrm{CI}=1.07-1.15)$, and 1.17 $(95 \% \mathrm{CI}=1.07-1.27)$, in this order. However $\mathrm{PM}_{10}$ and sulfur dioxide could not be associated with asthma in this study.

\section{DISCUSSION}

Our subjects participating in this study of the association between air pollution and asthma were usually school-aged children. Occupational exposure and regular smoking are causes of asthma that can be readily discounted in the case of primary and junior high school students. Thus all junior high school students in the Kaohsiung and Pintong areas of Tawian formed part of our study population. As response rate in this study was nearly $96.9 \%$, there was little or no selection bias. The characteristics of air pollution in Kaohsiung and Pintong countries are as follows. (a) Severe air pollution: the standard annual average value of TSP in Taiwan was $130 \mu \mathrm{g} / \mathrm{m}^{3}$. TSP deposition values were over $130 \mathrm{~g} / \mathrm{m}^{3}$ in 14 monitoring stations located in the Pintong and Kaohsiung areas. The 14 $\mathrm{PM}_{10}$ stations levels exceeded $65 \mu \mathrm{g} / \mathrm{m}^{3}\left(\mathrm{PM}_{10}\right.$ standard annual average value). The other pollutants are the same as above. (b) Pollution was related mostly to factories, which were near residential quarters. Almost $50 \%$ of petrochemical factories were located within $100 \mathrm{~m}$ of residential areas. Pollution levels in Taiwan at the time of our study were even higher than those observed for Switzerland with moderate average air pollution concentrations (Braun-Fahrlander et al., 1997). The effects of long-term, high average level air pollution to asthma were discussed in this largescaled study.

According to the video developed by the International Study of Asthma and Allergies in Childhood with high validity, the prevalence of childhood asthma can be compared among different countries (ISSAC steering committee, 1998; Pearce et al., 1993). In comparison lifetime prevalence of asthma was $18.5 \%$; prevalence of asthma in the preceding 12 months was $12.5 \%$; and rate of multiple attacks within a month was $5.2 \%$ in the present study using ISAAC questionnaire. We have found that boys suffered from asthma significantly more frequently than girls and there was a significant excess of asthma cases among young children. The association between social class and asthma was somewhat controversial. We detected a significant excess of asthma cases among children whose parents were highly educated, agreeing again with the finding of a previous study (Kaplan et al., 1988). Alcohol drinking has a large effect after adjustment for confounding factors in this present study. Alcohol elevates blood acetaldehyde, which leads to 
TABLE 4

Univariate Analysis and Adolescent Asthma and Outdoor Air Pollution

\begin{tabular}{|c|c|c|c|c|}
\hline Variable & Asthma $n(\%)$ & Nonasthma $n(\%)$ & OR & $95 \% \mathrm{CI}$ \\
\hline \multicolumn{5}{|c|}{ Total suspended particulate } \\
\hline$<181 \mu \mathrm{g} / \mathrm{m}^{3}$ & $6156(12.99)$ & $41234(87.01)$ & 1 & \\
\hline$\geq 181 \mu \mathrm{g} / \mathrm{m}^{3}$ & 8890 (16.43) & $45216(83.57)$ & $1.32^{* *}$ & $(1.27-1.36)$ \\
\hline \multicolumn{5}{|l|}{$\mathrm{PM}_{10}$} \\
\hline$<80 \mu \mathrm{g} / \mathrm{m}^{3}$ & $3719(15.32)$ & $20559(84.68)$ & 1 & \\
\hline$\geq 80 \mu \mathrm{g} / \mathrm{m}^{3}$ & $12610(14.64)$ & $73548(85.36)$ & $0.95^{* *}$ & $(0.91-0.99)$ \\
\hline \multicolumn{5}{|l|}{ Sulfur dioxide } \\
\hline$<0.013 \mathrm{ppm}$ & 7504 (14.46) & $44400(85.54)$ & 1 & \\
\hline$\geq 0.013 \mathrm{ppm}$ & $8825(15.08)$ & 49707 (84.92) & $1.05^{* *}$ & $(1.02-1.09)$ \\
\hline \multicolumn{5}{|l|}{ Nitrogen dioxide } \\
\hline$<0.028 \mathrm{ppm}$ & $3791(13.47)$ & $24344(86.53)$ & 1 & \\
\hline$\geq 0.028 \mathrm{ppm}$ & $12538(15.23)$ & $69763(84.77)$ & $1.15^{* *}$ & $(1.10-1.20)$ \\
\hline \multicolumn{5}{|l|}{ Carbon monoxide } \\
\hline$<0.80 \mathrm{ppm}$ & 3645 (13.11) & $24151(86.89)$ & 1 & \\
\hline$\geq 0.80 \mathrm{ppm}$ & 11695 (15.70) & $62773(84.30)$ & $1.23^{* *}$ & $(1.19-1.28)$ \\
\hline \multicolumn{5}{|l|}{ Ozone } \\
\hline$<0.022 \mathrm{ppm}$ & 7430 (14.59) & $43483(85.41)$ & 1 & \\
\hline$\geq 0.022 \mathrm{ppm}$ & $7721(15.49)$ & $42130(84.51)$ & $1.07 * *$ & $(1.04-1.11)$ \\
\hline \multicolumn{5}{|c|}{ Carbon hydrogen compound } \\
\hline$<0.45 \mathrm{ppm}$ & $6118(14.12)$ & 37209 (85.88) & 1 & \\
\hline$\geq 0.45 \mathrm{ppm}$ & $3943(13.85)$ & $24530(86.13)$ & 0.98 & $(0.94-1.02)$ \\
\hline \multicolumn{5}{|l|}{ Airborne dust particles } \\
\hline$<7.6$ ton $/ \mathrm{km}^{2} /$ month & $6131(13.39)$ & 39667 (86.61) & 1 & \\
\hline$\geq 7.6$ ton $/ \mathrm{km}^{2} /$ month & $8915(16.01)$ & 46783 (83.99) & $1.23^{* *}$ & $(1.19-1.28)$ \\
\hline
\end{tabular}

Note. The median value of the 1995 levels for $\mathrm{CO}, \mathrm{NO}_{2}, \mathrm{SO}_{2}$, airborne dust, $\mathrm{O}_{3}$, TSP, and hydrocarbon compounds were used to analyze the association between asthma and air pollution.

$* * P<0.01$.

degranulation of mast cells and releases histamine, induce asthma (Shimoda et al., 1996). The mechanisms of alcohol-induced bronchial asthma are suggested.

Exposure to air pollution was estimated in this study from outdoor levels monitored at stations set up in 24 districts located in the Kaohuiung and Pintong areas. The relationship between outdoor air pollution and asthma are performed in this study after other risk factors were controlled. Multiple regression analysis indicated that long-term exposure from TSP, $\mathrm{NO}_{2}, \mathrm{CO}, \mathrm{O}_{3}$, and airborne dust was associated with increased prevalence of asthma. Airborne particulate matter has been documented to be associated with a variety of adverse health impacts in children. These included a rise in very severe episodes, increased incidence of respiratory symptoms, and worsening impairment of lung function (Duhme et al., 1998; von Mutius et al., 1995). In a German study (Duhme et al., 1998), in which 18549 - to 11-year-old students were screened for upper respiratory symptoms, nitric oxide, TSP, and sulfur dioxide were suggested to be related to asthma either independently or synergistically. In our study, $\mathrm{SO}_{2}$, and $\mathrm{PM}_{10}$ contributed little to the prevalence of asthma. Sulfur dioxide was found to be significantly associated with adolescent asthma before controlling confouders. Asthmatics are particularly sensitive to $\mathrm{NO}_{2}$, with decrements in lung function demonstrated at levels $<0.3 \mathrm{ppm}$ (Bauer et al., 1986). A $10 \mathrm{mg} / \mathrm{m}^{3}$ increase in average home outdoor and personal exposure to $\mathrm{NO}_{2}$ was associated with a change in average FVC by $-0.59 \%$ and $-0.74 \%$, respectively (Schindler et al., 1998). Respiratory rate increased, epithelial lung permeability of the airway increased (Abramson et al., 1995), mucociliary clearance was altered (Foster et al., 1987) after exposure to ozone, and so did some pulmonary function indices, such as the $\mathrm{FEV}_{1}$ in $10-20 \%$ of persons who inspired $\mathrm{O}_{3}$ (Hazucha et al., 1987). Exposure to ozone and $\mathrm{NO}_{2}$ is associated with the symptoms of impaired lung function, bronchial hyperresponsiveness, and hospital presentations for asthma (Abramson et al., 1995).

People spend most of their time indoors (about $78 \%-90 \%$ ). Therefore, in addition to the effects of outdoor air pollution, it is important to consider the effects that exposure to indoor air pollution may have on adolescent asthma. We have shown that smoking or exposure to secondary smoke increases the likelihood of contracting asthma in childhood, as indicated by the dose-response relationship between asthma 
TABLE 5

Multivariate Analysis of the Demographic Characteristics and Indoor Air Pollution for Adolescent Asthma (Model 1)

\begin{tabular}{|c|c|c|c|c|}
\hline Variables & $\begin{array}{c}\text { Asthma } \\
n(\%)\end{array}$ & $\begin{array}{c}\text { Nonasthma } \\
n(\%)\end{array}$ & $\mathrm{AOR}^{a}$ & $95 \% \mathrm{CI}$ \\
\hline \multicolumn{5}{|l|}{ Sex } \\
\hline Female & $9422(12.01)$ & 69032 (87.99) & 1 & \\
\hline Male & $11215(14.60)$ & $65614(85.40)$ & $1.31^{* *}$ & $(1.27-1.36)$ \\
\hline \multicolumn{5}{|l|}{ Age } \\
\hline $11-12$ years & 5217 (14.85) & 29925 (85.15) & 1 & \\
\hline $13-14$ years & $13741(13.05)$ & 91563 (86.95) & $0.87 * *$ & $(0.84-0.90)$ \\
\hline $15-16$ years & $1679(11.32)$ & $13159(88.68)$ & $0.75^{* *}$ & $(0.70-0.79)$ \\
\hline \multicolumn{5}{|l|}{ Residence } \\
\hline Pintong County & $3722(9.58)$ & 35149 (90.42) & 1 & \\
\hline Kaohsiung County & $6188(12.92)$ & $41712(87.08)$ & $1.35^{* *}$ & $(1.30-1.41)$ \\
\hline Kaohsiung City & $10727(15.66)$ & $57786(84.34)$ & $1.60^{* *}$ & $(1.54-1.67)$ \\
\hline \multicolumn{5}{|l|}{ Parents'education } \\
\hline Primary school & $3515(10.86)$ & 28865 (89.14) & 1 & \\
\hline High school & $12664(13.25)$ & 82913 (86.75) & $1.18^{* *}$ & $(1.14-1.23)$ \\
\hline College & 4458 (16.31) & 22869 (83.69) & $1.41^{* *}$ & $(1.34-1.48)$ \\
\hline \multicolumn{5}{|l|}{ ETS } \\
\hline No & 8425 (13.18) & $55493(86.82)$ & 1 & \\
\hline Yes & 12212 & $79152(86.63)$ & $1.08 * *$ & $(1.0$ \\
\hline \multicolumn{5}{|l|}{ Chinese incense } \\
\hline No & $11244(13.99)$ & $69145(86.01)$ & 1 & \\
\hline Yes & $9236(12.56)$ & $64297(87.44)$ & $0.95^{* *}$ & $(0.92-0.98$ \\
\hline \multicolumn{5}{|l|}{ Exercise habit } \\
\hline No & 3139 (15.19) & $17522(84.81)$ & 1 & \\
\hline Seldom & $9961(13.20)$ & $65482(86.80)$ & $0.82^{* *}$ & $(0.78-0.85)$ \\
\hline Usually & $7487(12.73)$ & $51332(87.27)$ & $0.72 * *$ & $(0.69-0.76)$ \\
\hline \multicolumn{5}{|l|}{ Cigarette smoking } \\
\hline No & $19864(13.17)$ & 131016 (86.83) & 1 & \\
\hline Yes & $696(18.49)$ & $3068(81.51)$ & $1.29 * *$ & $(1.17-1.42)$ \\
\hline \multicolumn{5}{|l|}{ Alcohol drinking } \\
\hline No & $19927(13.12)$ & 131943 & 1 & \\
\hline Yes & $620(23.46)$ & $2023(76.54)$ & $1.85^{* *}$ & $(1.67-2.05)$ \\
\hline
\end{tabular}

${ }^{a} \mathrm{AOR}$, adjusted odds ratio.

$* * P<0.01$

and passive smoking reported in previous studies (Cunningham et al., 1996; Keil et al., 1992; NewmanTaylor et al., 1995; Sherman et al., 1990). The way passive smoking affects asthma is still a mystery. Thus to prevent childhood asthma or its exacerbation, the elimination of passive smoking from childern's environment is essential. In addition to exposure to tobacco smoke, the presence of dampness, molds, dust mites, pets, and mosquito incense are frequent causes of allergy in asthmatic persons (Chang et al., 1989; Dales et al., 1991; Dijkstra et al., 1990; Hosein et al., 1989; Peat et al., 1996). Chinese incense, however, seems to have a protective effect for people liable to suffer from asthma, even though according to Lin (Lin et al., 1993) it includes traces of formaldehyde, a suspected allergen. This curious phenomenon is worthy of study.

The appropriateness of pollution measurement is worth discussion. In this study, the outdoor air pollution concentrations were measured at 24 stations. The students who lived in the same community have the same air monitoring exposure levels from the same air station. Individual air pollution exposure was not assessed. The students who lived in the areas without monitoring stations in sparsely populated rural districts and the aboriginal reservation areas were excluded in this study; $72.6 \%$ effect size was observed for the association between asthma and outdoor air pollution. These areas have almost no air monitoring stations located in remote suburban and rural districts with a low asthma prevalence rate, low population density, few factories, and light traffic. The population densities are almost lower than 1000 people $/ \mathrm{km}^{2}$, even as low as 5 people $/ \mathrm{km}^{2}$. The pollutant-related odds ratio is not large biased.

The studies suggested that a viral infection of the respiratory system may cause asthma (Folkerts et al., 1998); therefore it may be an infectious chronic inflammatory disease. The influence of diet in asthma control remains unclear. Dietary antioxidants may influence the expression of asthma and have a modulatory effect on bronchial reactivity (Woods et al., 1996). Genetic heredity (Sandford et al., 1996; Holgate et al., 1997) had been proposed as a important etiological factor.

\section{CONCLUSION}

Our data demonstrate significant relationships between passive smoking, long-term outdoor air pollution, and adolescent asthma. We found that asthma was significantly related to high levels of nitrogen dioxide, ozone, carbon monoxide, airborne dust particles, and total suspended particulate with an 8 to

\section{TABLE 6}

Multivariate Analysis of Adolescent Asthma and Outdoor Air Polluation

\begin{tabular}{llll}
\hline Model & \multicolumn{1}{c}{ Variables included } & $\mathrm{AOR}^{a}$ & 95\% CI \\
\hline 1 & $\begin{array}{l}\text { Exercise + smoking + alcohol+incense } \\
\text { using + ETS }\end{array}$ & & \\
& Model 1 + total suspended particulate & $1.29^{* *}$ & $(1.24-1.34)$ \\
2 & Model 1 + $\mathrm{PM}_{10}$ & 1.00 & $(0.96-1.05)$ \\
4 & Model 1 + sulfur dioxide & 0.98 & $(0.95-1.02)$ \\
5 & Model 1 + nitrogen dioxide & $1.08^{* *}$ & $(1.04-1.13)$ \\
6 & Model 1 + carbon monoxide & $1.15^{* *}$ & $(1.10-1.20)$ \\
7 & Model 1 + ozone & $1.11^{* *}$ & $(1.07-1.15)$ \\
8 & Model 1 + airborne dust particles & $1.17^{* *}$ & $(1.07-1.27)$ \\
\hline
\end{tabular}

Note. There were adjustments for age, sex, resident area, and parents education level for Model 1 to Model 8.

${ }^{a} \mathrm{AOR}$, adjusted odds ratio of air pollution related.

$* * P<0.01$. 
$29 \%$ increase of asthma risk, after controlling for potential confound variables. To improve asthmatic children's health status a public health approach is required that emphasize disease prevention rather than a traditional medical approach. Protective standards must be laid down, involving the improvement of social cultural, and environmental conditions in which children live.

\section{ACKNOWLEDGMENTS}

We thank the Environmental Protective Administration, the Executive Yuan for supporting this study (Grant No. EPA85-1601-0805).

\section{REFERENCES}

Abramson, M. J., Marks, G. B., and Pattemore, P. K. (1995). Are nonallergenic environmental factors important in asthma? Med. J. Australia 163(10), 542-545.

Bauer, M. A., Utell, M. J., Morrow, P. E., Speers, D. M., and Gibb, F. R. (1986). Inhalation of $0.3 \mathrm{ppm}$ nitrogen dioxide potentiates exercise-induced bronchospasm in asthmatics. Am. Rev. Respir. Dis. 134, 1203-1208.

Braun-Fahrlander, C., Vuille, J. C., Sennhauser, F. H., Neu, U., Kunzle, T., Grize, L., Minder, G. C., Schinder, C., Varonier, H. S., Wuthrich, B., and the Scarpol team (1997). Respiratory health and long term exposure to air pollutants in Swiss schoolchildren. Am. J. Respir. Crit. Care Med. 155, 1042-1049.

Chang,Y. C., and Hsieh, K. H. (1989). The study of house dust mites in Taiwan. Ann. Allergy 62, 101-106.

Chinn, S., and Rona, R. J. (1991). Quantifying health aspects of passive smoking in British children aged 5-11 years. J. Epidemiol. Community Health 45, 188-194.

Chitano, P., Hosselet, J. J., Mapp, C. E., and Fabbri, L. M. (1995). Effect of oxidant air pollutants on the respiratory system; insight from experimental animal research. Eur. Respir. J. 8, 1357-1371.

Cunningham, J., O‘Connor, G. T., Dockery, D. W., and Speizer, F. E. (1996). Environmental tobacco smoke, wheezing and asthma in 24 communities. Am. J. Respir. Crit. Care. Med.153, 218-224.

Dales, R. E., Zwanenburg, H., Burnett, R., and Franklin, C. A. (1991). Respiratory health effects of home dampness and moulds among Canadian children. Am. J. Epidemiol. 134, 196-203.

Dockery, D. W., Scewartz, J., and Spengler, J. D. (1992). Air pollution and daily mortality: Associations with particulates and acid aerosols. Environ. Res. 9, 362-373.

Duhme, H., Weiland, S. K., Rudolph, P., Wienke, A., Kramer, A., and Keil, U. (1998). Asthma and allergies among children in West and East Germany: A comparison between Munster and Greifswald, using the ISAAC phase I protocal. Eur. Respir. J. 11, 840-847.

Evans, R., Webb, K., Homan, S., and Ayres, S. M. (1988). Cross-sectional and longitudinal changes in pulmonary function associated with automobile pollution among bridge and tunnel officers. Am. J. Int. Med. 14, 25-36.

Folkerts, G., Busse, W.W., Nijkamp, F. P., et al. (1998). Virus induced airway hyperresponsiveness and asthma. Am. J. Respir. Crit. Care. Med. 157, 1708-1720.

Forastiere, F., Corbo, G. M., Michelozzi, P., Pistelli, R., Agabiti, N., Brancato, G., Ciappi, G., and Perucci, C. A. (1992). Effects of environment and passive smoking on the respiratory health of children. Int. J. Epidemiol. 21, 66-73.
Foster, W. M., Costa, D. L., and Langenback, E. G. (1987). Ozone exposure alters tracheobronchial mucociliary function in human. Am. J. Physiol. 63, 996-1002.

Hazucha, M. J. (1987). Relationship between ozone exposure and pulmonary function changes. J. Appl. Physiol. 62, 1671-1680.

Holgate, S. T. (1997). Asthma genetics: Waiting to exhale. Nature Genet. 15, 227-229.

Hosein, H. R., Corey, P., and Robertson, J. M. (1989). The effect of domestic factors on respiratory symptoms and FEV. Int. J. Epidemiol. 18, 390-396.

Kaplan, B. A., and Mascie-Taylor, C. G. N. (1988). Asthma and wheezy bronchitis in adolescents: Biosocial correlates. J. Asthma 25, 125-129.

Keil, U., and Weiland, S. K. (1992). International asthma and allergy study. Lancet 340, 46.

Ko, Y. C. (1996). Air pollution and its health effects on residents in Taiwanese communities. Kaohsiung J. Med. Sci. 12, 657-669.

Lebowitz, M. D., Collins, L., and Holberg, C. J. (1987). Time series analysis of respiratory response to indoor and outdoor environmental phenomena. Environ. Res. 43, 332-341.

Lin, J. M., and Yao, Y. H. (1993). Formaldehyde in conventional homes in Taiwan. Environ. Int. 19, 561-568.

Neas, L. M., Dockery, D.W., and Koutrakis, P. (1995).The association of ambient air pollution with twice daily peak expiratory flow rate measurements in children. Am. J. Epidemiol. 141, $111-122$.

Newman-Taylor, A. (1995). Environmental determinants of asthma. Lancet 345, 296-299.

Pearce, N., Weiland, S., Keil, U., Langridge, P., Anderson, H. R., Strachan, D., Bauman, A., Young, A., Gluyas, P., Ruffin, D., Crane, J., and Beasley, R. (1993). Self-reported prevalence of asthma symptom in children in Australia, England, Germany and New Zealand: An international comparison using the ISAAC protocol. Eur. Respir. J. 6, 1455-1461.

Peat, J. K., Tovey, E., Toelle, B. G., Haby, M. M., Gray, E. J., Mahmic, A., and Woolcock, A. J. (1996). House dust mite allergens: A major risk factor for childhood asthma in Australia. Am. J. Respir. Crit. Care. Med. 153, 141-146.

Samet, J. M., Marbury, M. C., and Spengler, J. D. (1987). Health effects and sources and of indoor air pollution, Part I. Am. Rev. Respir. Dis. 136, 1486-1508.

Sandford, A., Weir, T., and Pare, P. (1996). The genetics of asthma. Am. J. Respir. Crit. Care Med. 153, 1749-1765.

Schindler, C., Ackermann-Liebrich, U., Leuenberger, P., et al. (1998). Association between lung function and estimated average exposure to $\mathrm{NO}_{2}$ in eight areas of Switzerland. The SAPALDIA team. Swiss study of Air Pollution and Lung Diseases in Adults. Epidemiology 9(4), 405-411.

Schwartz, J. (1989). Lung function and chronic exposure to air pollution: A cross-sectional analysis of NHANES II. Environ. Res. 50, 309-321.

Shaw, R. A., Crane, J., Pearce, N., Burgess, C. D., Bremner, P., Woodman, K., and Beasley, R. (1992). Comparison of a video questionnaire with the IUATLD written questionnaire for measurement asthma prevalence. Clin. Exp. Allergy 22, 561-568.

Sherman, C. B., Tosteson, T. D., Tager, I. B., Speizer, F. E., and Weiss, S. T. (1990). Early childhood predictors of asthma. Am. J. Epidemiol. 132, 83-95. 
Shimoda, T., Kohno, S., Takao, A., Fujiwara, C., Matsuse, H., Sakai, H., Watanabe, T., Hara, K., and Asai, S. (1996). Investigation of the mechanism of alcohol-induced bronchial asthma. J. Allergy Clin. Immunol. 97, 74-84.

Stoddard, J. J., and Miller, T. (1995). Impact of parental smoking on the prevalence of wheezing respiratory illness in children. Am. J. Epidemiol. 141(2), 96-102.

The international study of asthma and allergies in Childhood (ISAAC) steering committee. (1998). Worldwide variation in preva- lence of symptoms of asthma, allergic rhinoconjunctivitis, and atopic eczema: ISAAC. Lancet 351, 1225-1232.

von Mutius, E., Sherrill, D. L., Fritzsch, C., Martinez, F. D., and Lebowitz, M. D. (1995). Air pollution and upper respiratory symptoms in children from East Germany. Eur. Respir. J. 8, 723-728.

Woods, R. K., Weiner, J., Abramson, M., Thien, F., and Walter, E. H. (1996). Patients perceptions of food-induced asthma. Australian N. Zealand J. Med. 26, 504-512. 